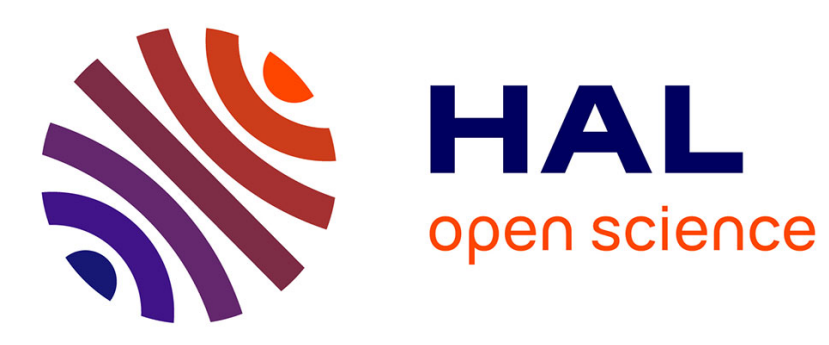

\title{
Implicit long-term memory for duration in young children
}

Anne-Claire Rattat, Sylvie Droit-Volet

\section{To cite this version:}

Anne-Claire Rattat, Sylvie Droit-Volet. Implicit long-term memory for duration in young children. European Journal of Cognitive Psychology, 2007, 19 (2), pp.271-285. 10.1080/09541440600834647 . hal-02053587

\section{HAL Id: hal-02053587 \\ https://hal.science/hal-02053587}

Submitted on 13 Mar 2019

HAL is a multi-disciplinary open access archive for the deposit and dissemination of scientific research documents, whether they are published or not. The documents may come from teaching and research institutions in France or abroad, or from public or private research centers.
L'archive ouverte pluridisciplinaire HAL, est destinée au dépôt et à la diffusion de documents scientifiques de niveau recherche, publiés ou non, émanant des établissements d'enseignement et de recherche français ou étrangers, des laboratoires publics ou privés. 
This article was downloaded by:[U F R de Psychologie]

On: 29 J anuary 2007

[U F R de Psychologie]

Access Details: [subscription number 731667045]

Publisher: Psychology Press

Informa Ltd Registered in England and Wales Registered Number: 1072954

Registered office: Mortimer House, 37-41 Mortimer Street, London W1T 3J H, UK

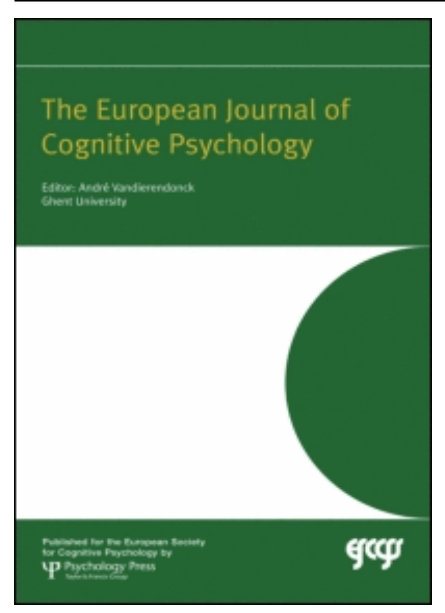

\section{European J ournal of Cognitive Psychology}

Publication details, including instructions for authors and subscription information: http://www.informaworld.com/smpp/title content=t713734596 Implicit long-term memory for duration in young children

First Published on: 10 J uly 2006

To link to this article: DOI: $10.1080 / 09541440600834647$

URL: http://dx.doi.org/10.1080/09541440600834647

Full terms and conditions of use: http://www.informaworld.com/terms-and-conditions-of-access.pdf

This article maybe used for research, teaching and private study purposes. Any substantial or systematic reproduction, re-distribution, re-selling, loan or sub-licensing, systematic supply or distribution in any form to anyone is expressly forbidden.

The publisher does not give any warranty express or implied or make any representation that the contents will be complete or accurate or up to date. The accuracy of any instructions, formulae and drug doses should be independently verified with primary sources. The publisher shall not be liable for any loss, actions, claims, proceedings, demand or costs or damages whatsoever or howsoever caused arising directly or indirectly in connection with or arising out of the use of this material.

(c) Taylor and Francis 2007 


\title{
Implicit long-term memory for duration in young children
}

\author{
Anne-Claire Rattat \\ Jean-François Champollion University, Albi, France \\ Sylvie Droit-Volet \\ LAPSCO, CNRS, Blaise Pascal University, Clermont-Ferrand, France
}

\begin{abstract}
The aim of the present study was to investigate young children's ability to maintain in long-term memory a duration of an action they have previously experienced (i.e., implicit long-term memory for duration). Children aged 3 and 5 years were trained to produce an action for $5 \mathrm{~s}$ by simultaneous imitation of the experimenter's action. Then, they were tested after a retention interval lasting for 1, 24, or 48 hours (Experiment 1), or 6 days, 6 weeks, or 6 months (Experiment 2). The results showed that the young children remembered the learned duration after 48 hours and 6 months at the age of 3 and 5 years, respectively, although the temporal performance decreased at the 1 hour and the 6 weeks retention intervals for the first and the second age group. These findings are discussed in the framework of a discrepancy in the memory retention of duration as a function of the nature of the memory system, i.e., implicit or explicit.
\end{abstract}

Research related to long-term memory development for time has mainly focused on temporal order (e.g., Bauer \& Hertsgaard, 1993; Bauer, Hertsgaard, \& Dow, 1994; Bauer \& Mandler, 1989; Bauer \& Shore, 1987; Friedman, 1990; O'Connel \& Gerard, 1985) or temporal locations (e.g., Friedman, 1991; Friedman, Gardner, \& Zubin, 1995; Friedman \& Kemp, 1998; Tartas, 2001), but rarely on young children's abilities to recall the duration of an event they have previously experienced (Block, Zakay, \& Hancock, 1999; Droit-Volet, 2003b). However, Rattat and Droit-Volet (2005) have recently tested the effect of an interfering task and a retention

Correspondence should be addressed to Anne-Claire Rattat, Laboratoire Cognition, Communication et Développement (JE 2395-Université Toulouse le Mirail), CUFR JeanFrançois Champollion, Place Verdun, 81012 Albi Cedex 9, France.

E-mail: anne-claire.rattat@ univ-jfc.fr

We would like to express our thanks to the staff and children of the following nursery schools: "Maurice Grangier" in Blanzat, "Paul Lapie" in Chamalières, and "Jules Ferry" in ClermontFerrand (France), and to the inspectors of the state education system, without whom this study could not have been conducted.

(C) 2006 Psychology Press, an imprint of the Taylor and Francis Group, an informa business http://www.psypress.com/ecp

DOI: $10.1080 / 09541440600834647$ 
interval on temporal judgements in children aged 3-8 years in a bisection task. The bisection task consisted of a presentation phase, in which participants were shown five times in succession two referent durations that were explicitly identified as the short (e.g., $2 \mathrm{~s}$ ) and the long one (e.g., $8 \mathrm{~s})$. Then, in a learning phase, they received feedback that indicated whether each response was correct or not, which was intended to train the children to discriminate between these two referent durations. Finally, participants completed a testing phase, in which they were asked to judge whether each comparison duration just presented (e.g., 2, 3, 4, 5, 6, 7, and $8 \mathrm{~s}$ ) was more similar to the short or to the long referent duration previously learned. No feedback was provided during this phase. In the testing phase, the temporal judgement is thus assumed to result from the comparison of the just presented duration with the representation of the short and the long referent durations in long-term memory. Moreover, in their experiments, the interfering task or the retention interval, each lasting for $15 \mathrm{~min}$, was given between the learning and the testing phase. The results showed a decrease in temporal performance with $15 \mathrm{~min}$ of interference or retention interval. However, this decrease in performance became lower with age. Indeed, the comparison between the $15 \mathrm{~min}$ deferred test and the immediate test revealed that the 8-year-olds remembered the duration of the previously learned referents relatively well. In contrast, in the same conditions, the 3-year-olds were unable to correctly judge the similarity between the comparison and the referent durations, as indicated by their poorer temporal performance in the deferred test compared to the immediate test. As explained by Rattat and Droit-Volet, at the age of 3 years, the forgetting would have almost entirely deleted the referent durations in long-term memory. In comparison with the younger children, the 5-year-olds' temporal judgements were less affected by the 15 min memory retention of the referent durations. Nevertheless, after the interfering task or the retention interval, the 5-year-olds produced many errors of temporal judgement. Furthermore, the number of temporal errors they produced increased when the retention interval was lengthened from 15 min to 24 hours. Thus, in contrast to the younger children, the 8-year-olds' forgetting by interference or retention interval only introduced noise in their long-term memory representation of the referent durations.

The results obtained with the temporal bisection task suggested that there is an improvement between 3 and 8 years in the ability to maintain the duration of a stimulus in long-term memory. These findings are consistent with those of studies on the development of long-term memory, which showed a substantial increase of long-term retention capacities with age (for reviews, see Howe \& Brainerd, 1989; Kail, 1990; Schneider, 2000). However, the memory tasks used in this kind of study are associated with subjective awareness of engaging in recall, indicating that the development of the 
retention capacities has been observed in the case of explicit long-term memory. Explicit memory is specialised for rapid learning and corresponds to conscious memories of events (Anderson, 1983). In the temporal bisection task, despite the learning of the two referent durations, each of these durations was presented a relatively small number of times (i.e., between 9 and 25). Furthermore, as previously explained, children received the verbal instructions to deliberately remember the referent durations in long-term memory for comparison with the tested duration just presented, thus requiring that the children attend to time. Although the nature of the long-term memory for duration has actually never been discussed in the bisection task, we can also suggest that the age-related changes in long-term retention of durations in this task may be due to an explicit memory of time.

Recently, Lewis and Miall (2003) dissociated a cognitively controlled from an automatic timing system. The automatic timing system would be involved when a duration is "measured again and again without change or interruption ..., and produced continuously and via movement" (p. 518). This overlearned duration in movement recruits timing circuits within the motor system that can act without attentional modulation, i.e., the automatic timing system. The duration that is experienced via motor movement and that is overlearned implicates what we call procedural learning. Indeed, procedural learning is defined as the acquisition of new skills through practice without awareness; that is, the characteristics of these skills remain implicit (Anderson, 1983; DiGiulio, Seidenberg, O’Leary, \& Raz, 1994). Therefore, evaluation of children's capacity to maintain in memory a duration that is experienced continuously and via motor movement, as in the present study, refers to a procedural or implicit measure of time memory. By definition, procedural or implicit memory indeed requires a repeated presentation of stimuli and is evidenced by tasks that reveal facilitative effects of prior exposure, without requiring conscious recollection (Tulving, 1985).

In the child development literature, the age-related improvement for explicit memory classically contrasts with an absence of age differences for implicit memory (Anooshian, 1997, 1998, 1999; Bauer, 1997; DiGiulio et al., 1994; Greenbaum \& Graf, 1989; Naito, 1990; Parkin \& Streete, 1988; Russo, Nichelli, Gibertoni, \& Cornia, 1995). Indeed, the usual finding of implicit memory studies is that children are only minimally sensitive to forgetting. However, Murphy, McKone, and Slee (2003) have recently highlighted that, in these studies, implicit memory has exclusively been evaluated in domains for which there is little or no change in the relevant knowledge base across the age range tested. Their developmental study was the first to demonstrate that implicit memory clearly improves with age increasing, when the underlying knowledge base is subjected to simultaneous development. Knowledge for duration is known to develop across childhood, and more 
particularly between the age of 3 and 5 years (for reviews, see Droit-Volet, 2000; Droit-Volet, Delgado, \& Rattat, 2005). More precisely, our previous studies consistently described, during this age range, the passage from an implicit procedural duration knowledge, which is a knowledge of the duration associated with a specific action that the children have repeatedly experienced, to an explicit knowledge of time (Droit, 1995; Droit-Volet, 1998; Droit-Volet \& Rattat, 1999; Rattat \& Droit-Volet, 2002). In contrast to 5-years-olds, 3-year-olds failed to transfer the duration learned by imitation with an action to another action. This finding suggested that time and action are not conceptually dissociated in children's time estimation before the age of 5 years (Droit-Volet, 1998). Within this theoretical framework, we expected not only that, in young children, the long-term implicit memory for duration would be better than the explicit memory for duration, which has been previously examined with the bisection task (Rattat \& Droit-Volet, 2005), but also that the implicit memory for duration would improve between the age of 3 and 5 years.

The aim of the present study was thus to run a first experiment in order to investigate long-term retention of implicit memory for duration in young children, an issue that has been completely unexplored until now. In line with Lewis and Miall (2003), and in order to examine an implicit memory for duration, the 3- and 5-year-olds were trained on several sessions to produce an action in temporal synchronisation with the experimenter's action (see Droit-Volet \& Rattat, 1999; Rattat \& Droit-Volet, 2002). Since the duration would be automatically encoded with its action (Michon, 1990), we can supposed that, in these conditions, it would be the action associated with its duration that the young children learning, rather than the duration itself. Thus, if after a delay children succeeded in reproducing the appropriate action and its associated duration without any specific instructions about time, then it could be assumed that children recalled the action and retained an implicit memory of its duration.

\section{EXPERIMENT 1}

In Experiment 1, we trained 3- and 5-year-old children to produce a duration action with a simultaneous imitation procedure. In this procedure, the children learned to produce the duration action $(5 \mathrm{~s})$ in synchronisation with the experimenter's action without any particular verbal instructions, the experimenter only saying: "Do exactly as I do". The action made a smiling clown appear on the computer screen. Then, in order to evaluate the children's capacity to maintain the target acted duration in memory, they were tested in the same setting in which they were trained after a retention 
interval of 1,24 , or 48 hours had passed. The experimenter simply instructed the children to play at making the smiling clown appear.

\section{Method}

Participants. The sample consisted of 60 children: thirty 3-year-olds (17 girls and 13 boys; mean age $=3.31, S D=0.34$ ), and thirty 5-year-olds ( 8 girls and 22 boys; mean age $=5.22, S D=0.27$ ). They were recruited from nursery schools in Blanzat, Chamalières, and Clermont-Ferrand, France. All children were volunteered and received their parents' agreement to participate in this experiment.

Materials. Each child was seated in a quiet room in front of a Power Macintosh computer that controlled the experiment and recorded data via PsyScope software (Cohen, MacWhinney, Flatt, \& Provost, 1993). Responses were made using the spacebar of the computer keyboard. Pressing the spacebar resulted in the appearance of a blue circle $(4.5 \mathrm{~cm}$ in diameter) in the centre of the computer screen, and releasing the key in its disappearance. The feedback, displayed for $3 \mathrm{~s}$ in the centre of the computer screen, was the face of a clown who was either smiling for accurate response durations or frowning for inaccurate ones. In the learning phases, the experimenter had her own computer keyboard, similar to the child's one.

Procedure. The children's task was to produce the target response duration of $5 \mathrm{~s}$. As in previous studies using a similar experimental procedure (Droit-Volet \& Rattat, 1999; Rattat \& Droit-Volet, 2002), when the response duration was between 4 and $6 \mathrm{~s}$, they obtained the smiling clown, and when it was less than $4 \mathrm{~s}$ or more than or equal to $6 \mathrm{~s}$, the frowning clown. Moreover, the frowning clown interrupted the response duration when it reached $13 \mathrm{~s}$.

The children were given successive learning sessions during which they performed a baseline phase (10 trials), a simultaneous imitation learning phase (20 trials), and an immediate retention phase (10 trials). The learning sessions terminated when the child reached, in the immediate retention phase, a fixed learning criterion: at least $60 \%$ of accurate response durations. In the baseline phase, the spontaneous response durations were collected. The experimenter only said: "Now, play alone at making the smiling clown appear." However, in order to be able to collect spontaneous produced durations, the experimenter added during the baseline phase of the first session: "To make the smiling clown appear, you must press this key for a certain time. If you press it for the right time, you'll get the smiling clown. If you don't press it for the right time, you'll get the frowning clown." Then, in the experimental session, the children were given any other instructions 
related to duration. In the imitation phase, the experimenter only told them to imitate her behaviour while saying: "We're going to make smiling clown appear together. Do exactly as I do." For the first trial only, the experimenter pressed with her right hand on her own computer keyboard for $5 \mathrm{~s}$ while pressing the child's hand on his/her keyboard with her left hand. Then, she simultaneously released her two hands, and added: "We've played well, we've got the smiling clown! If we hadn't played well, we would have gotten the frowning clown." Before each trial, the experimenter simply repeated: "Ready, let's do exactly as I do", and made sure that the child synchronised his/her press with hers. Then, to evaluate the effect of this imitation learning on his/her response durations, the child was given an immediate retention phase; the experimenter said: "Now, play alone."

In order to test their long-term memory retention of the learned response duration, the children were then given a deferred retention phase (10 trials) that was identical to the immediate retention phase. They were simply told to play alone at making the smiling clown appear without any allusion to duration. In each age group, children were randomly assigned to one experimental condition as a function of the duration of the retention interval, i.e., 1,24 , or 48 hours.

\section{Results and discussion}

Imitation learning. Figure 1 shows the mean proportion of accurate durations obtained by the 3- and the 5-year-olds as a function of the retention interval condition in the baseline phase of the first learning session, the immediate retention phase of the last learning session and the deferred retention phase. To ensure that all children had learned to produce the target duration with the simultaneous imitation instructions, we calculated, for each child, the difference between the mean proportion of accurate durations produced after (immediate retention phase) and before (baseline phase) this learning. This difference significantly differed from zero, whatever the experimental condition, and in the two age groups: 3-year-olds: 1 hour, $t(9)=8.96, p<.05 ; 24$ hours, $t(9)=8.27, p<.05 ; 48$ hours, $t(9)=10.86$, $p<.05$; 5-year-olds: 1 hour: $t(9)=13.42, p<.05 ; 24$ hours, $t(9)=4.32$, $p<.05 ; 48$ hours, $t(9)=5.51, p<.05$. Children needed between 20 and 100 imitation trials (median $=40$ trials) to reach the learning criterion. Moreover, an analysis of variance ${ }^{1}$ (ANOVA) performed on these differences with two between-subjects factors (age and retention interval) revealed no significant effect: age, $F(1,60)=0.13, p>.05, \eta^{2}=.002$; retention interval, $F(2,60)=1.04, p>.05, \eta^{2}=.037$; Age $\times$ Retention interval, $F(2,60)=1.39$,

\footnotetext{
${ }^{1}$ Previous analyses revealed neither a significant main effect nor any interaction involving the number of learning session factors. Thus, this factor was not included in the statistical analyses.
} 

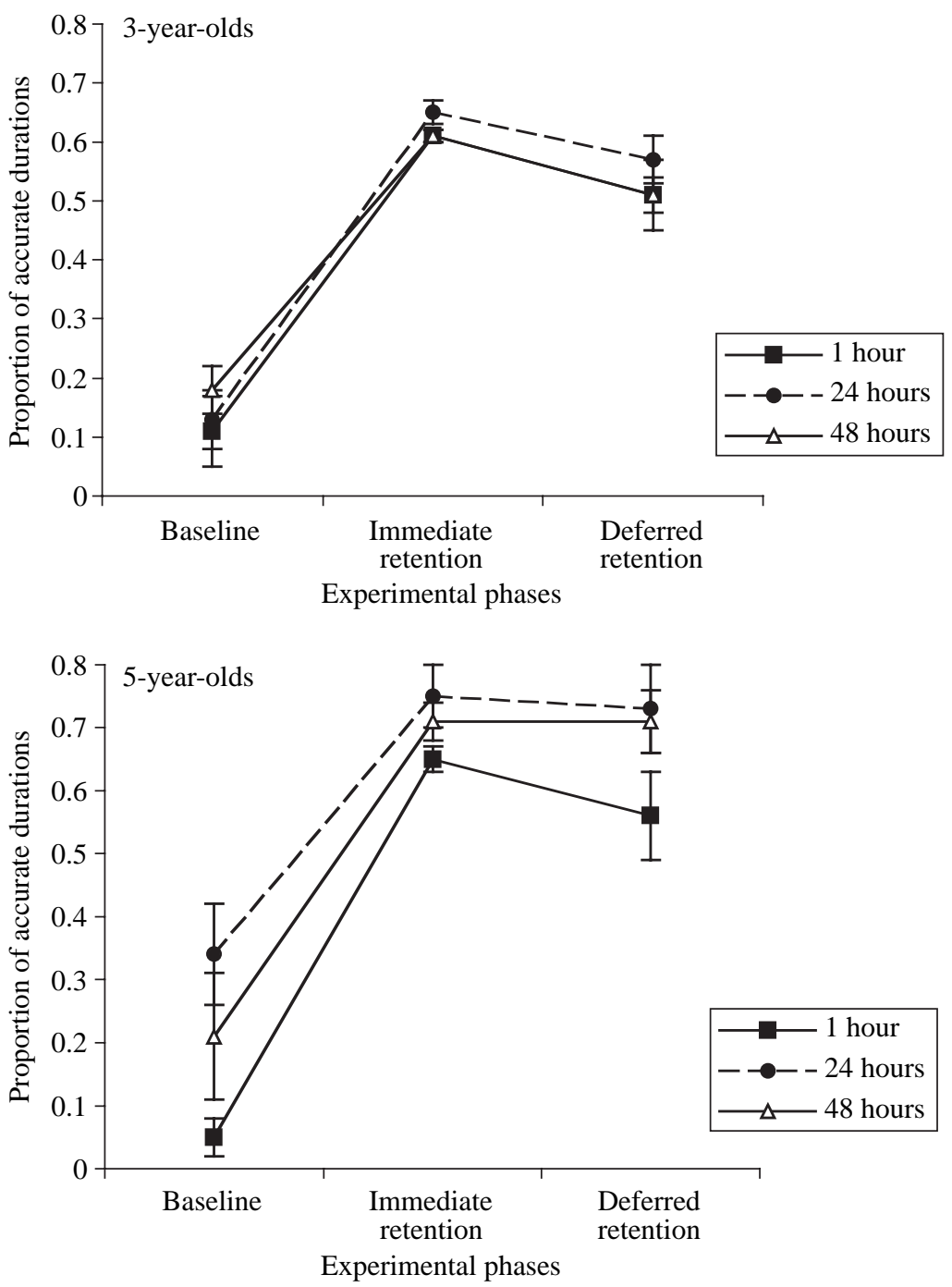

Figure 1. Proportion of accurate durations for the 3- and the 5-year-olds as a function of the retention interval ( 1 hour vs. 24 hours vs. 48 hours), in the different experimental phases: baseline (before the initial learning), immediate retention after the criterion learning achieved, and deferred retention.

$p>.05, \eta^{2}=.049$. This pattern of results thus confirmed that the children aged 3 and 5 years produced more accurate durations after than before the imitation learning, and that this difference was similar in the 3-and the 5-year-olds. 
Long-term retention. In order to see whether the response duration learned by simultaneous imitation was degraded by the retention interval, we calculated for each child the difference between the mean proportion of accurate durations produced after (deferred retention phase) and before (immediate retention phase) the retention interval. At the age of 5 years, whatever the retention interval, this difference did not statistically differ from zero: 1 hour, $t(9)=-1.41, p>.05 ; 24$ hours, $t(9)=-0.43, p>.05 ; 48$ hours, $t(9)=0, p>.05$. These results showed that the 5 -year-olds' temporal performance was not degraded by the retention interval, whatever its duration. As in the 5-year-olds, in the 3-year-olds, the difference between the proportion of accurate durations in the deferred and the immediate retention phases did not significantly differ from zero after a 1 hour retention interval, $t(9)=-1.94, p>.05$, suggesting that the children had not forgotten the target duration. However, it did differ after 24 hour and 48 hour retention interval, respectively, $t(9)=-2.23, p=.05$, and $t(9)=-3.35$, $p<.05$. Nevertheless, post hoc $t$-tests indicated that the 3 -year-olds produced more accurate durations in the deferred retention than in the baseline phase in both the 24 hour, $t(9)=6.13, p<.05$, and the 48 hour interval retention condition, $t(9)=9, p<.05$, thus suggesting that the target duration was not completely forgotten.

In sum, the 3-year-old children were able to maintain in long-term memory a duration action learned by simultaneous imitation, although there was a decrease in their temporal performance after 24 hour and 48 hour retention interval. Unlike the younger children, the 5-year-olds always obtained the same temporal performance, revealing that they did not forget the duration learned by simultaneous imitation after a 48 hour retention interval. Therefore, in a second experiment, we decided to increase the retention interval, for the 5-year-olds, to 6 days, 6 weeks, and 6 months in order to see whether longer retention interval led to a deterioration of their temporal performance.

\section{EXPERIMENT 2}

\section{Method}

A total of 30 new 5-year-olds (14 girls and 16 boys; mean age $=5.01, S D=$ 0.32 ) participated in Experiment 2. The materials were similar to those used in Experiment 1, as was the procedure, with the exception of the retention interval. For one group of 5 -year-olds $(n=10)$, the retention interval lasted for 6 days, for another one $(n=10)$ it lasted for 6 weeks, and for the last one $(n=10)$ it lasted for 6 months. 


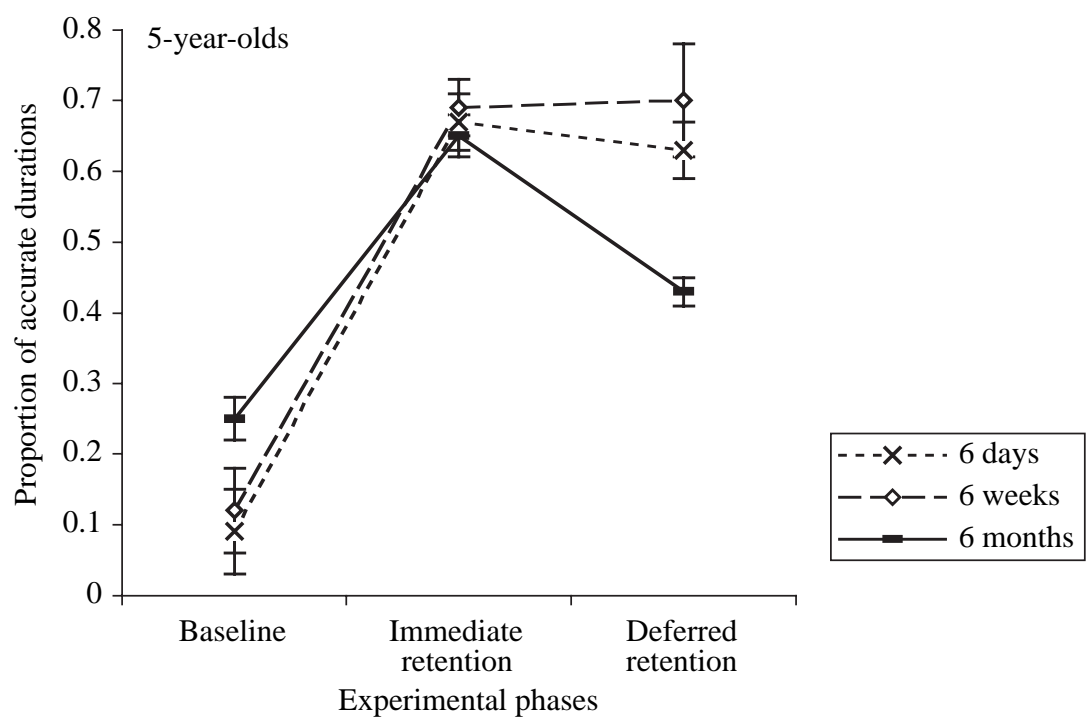

Figure 2. Proportion of accurate durations for the 5-year-olds as a function of the retention interval ( 6 days vs. 6 weeks vs. 6 months), in the different experimental phases: baseline (before the initial learning), immediate retention after the criterion learning achieved, and deferred retention.

\section{Results and discussion}

Figure 2 clearly shows that, in all experimental conditions, the 5-year-olds learned to produce the target duration ( $5 \mathrm{~s})$. They performed between 20 and 100 trials to reach the learning criterion (median $=40$ trials). Indeed, whereas they produced between $9 \%$ and $25 \%$ of accurate durations in the baseline, this percentage was higher than $65 \%$ in the immediate retention phase. This increase in temporal performance was significant in the three conditions, as indicated by the statistical analyses on the difference between the proportion of accurate durations in the immediate retention and in the baseline phase: 6 days, $t(9)=13.11, p<.05$; 6 weeks, $t(9)=6.60, p<.05$; and 6 months, $t(9)=9.49, p<.05$. Moreover, the ANOVA $^{2}$ performed on this difference with retention interval as between-subjects factor revealed that the increase in the number of accurate durations between the baseline and the immediate retention phase did not significantly change as a function on the retention interval, $F(2,30)=2.95, p>.05, \eta^{2}=.179$. All the 5-year-old children thus produced more accurate durations after than before the imitation learning.

\footnotetext{
${ }^{2}$ Previous analyses revealed neither a significant main effect nor any interaction involving the number of learning session factors. Thus, this factor was not included in the statistical analyses.
} 
Furthermore, as in Experiment 1, the difference between the proportion of accurate durations in the deferred and the immediate retention phase was not statistically different from zero after a 6 day and a 6 week retention interval: $t(9)=-0.69, p>.05$, and $t(9)=-0.15, p>.05$, respectively, indicating that there is no sign that the 5-year-old children had forgotten the target response duration learned by simultaneous imitation until 6 weeks. However, this difference reached statistical significance after 6 months of retention, $t(9)=-0.11, p<.05$. Nevertheless, in this last condition, the 5 -year-olds produced more accurate durations in the deferred retention than in the baseline phase, $t(9)=4.32, p<.05$, indicating that the target duration was not completely forgotten. To ensure that this did not reflect an eventual relearning of the required duration due to feedback (i.e., smiling or frowning clown), we also compared the mean proportion of accurate durations of the first five trials to that of the last five trials of the deferred retention phase. The performance was not better at the end than at the beginning of the retention phase (Wilcoxon test: $Z=-.138, p>.05$ ), thus suggesting that duration was not relearned. Overall, these results suggested that, at the age of 5 years, the children were able to keep in memory a duration action learned by simultaneous imitation, although their temporal performance decreased after a 6 month retention interval.

\section{GENERAL DISCUSSION}

Overall, the findings of the two present experiments showed that young children were able to learn and retain for a long period the duration of a given action previously experienced by simultaneous imitation. Their capacity to maintain durations in long-term memory thus appeared better in the imitation learning conditions tested in the present study than in the temporal bisection task previously tested by Rattat and Droit-Volet (2005). Indeed, as explained in the introduction, in Rattat and Droit-Volet's study, the 3- and the 5-year-olds' bisection performance showed degradation as soon as after $15 \mathrm{~min}$ of memory retention of the referent durations, although to a greater extent in the younger children. In contrast, in the present experimental conditions, the children of the same age did not forget the learned duration until 48 hours for the 3-year-olds and 6 months for the 5 -years olds, although the children's temporal performance decreased from 1 hour and 6 weeks in the first and the second age group, respectively.

Lewis and Miall (2003) have recently proposed that, according to the nature of long-term memory for time, the measurement of durations can be performed by a different timing system, i.e., a cognitively controlled timing system for explicit memory, and an automatic timing system for implicit memory. In our experiments, the target duration was the duration of a motor 
movement acquired through repeated practice by simultaneous imitation of the experimenter's action (procedural learning). Furthermore, our statistical analyses revealed that after a retention interval as long as 6 weeks or 6 months, the children did not relearn the required duration. We can thus suggest that the learning of the duration in these experimental conditions implicated an automatic timing system. Therefore, our study showed that young children have good long-term implicit memory for duration. Consequently, in comparison with the results obtained in temporal bisection by Rattat and Droit-Volet (2005), the long-term implicit memory for duration was better than the explicit memory for duration in children. This finding is consistent with those of developmental studies showing that implicit memory is less sensitive to forgetting than explicit memory (Anooshian, 1997, 1998, 1999; Bauer, 1997; DiGiulio et al., 1994; Greenbaum \& Graf, 1989; Naito, 1990; Parkin \& Streete, 1988; Russo et al., 1995). However, to conclude on the explicit versus implicit memory for duration issue, further investigations testing other experimental conditions and actions are required, as well as a direct comparison of performance between explicit and implicit memory conditions.

Although their temporal performance was better in the present than in the bisection task, the 3-year-olds still remembered the duration learned by imitation less than the 5-year-olds. Indeed, in contrast to the older children, for whom there was no sign of forgetting the learned duration until 6 weeks, the 3-year-olds' temporal performance decreased significantly after 1 hour of retention. Nevertheless, like the 5-years-olds after 6 months of retention, the 3 -year-olds did not completely forget the target duration after 24 hours or 48 hours of retention, as indicated by their higher performance in the deferred retention test than in the baseline phase. These results support the idea that an improvement during childhood exists for both implicit and explicit memory for duration, although their rate of development seems to differ. According to Murphy et al. (2003), implicit memory clearly improves with age only if the knowledge base required by the task is undergoing development during the age range tested. In the specific timing domain, several studies have documented differences in knowledge about duration for 3- and 5-year-old children (for a review, see Droit-Volet, 2000). More precisely, the 3-year-olds needed personal experience of an action to learn its duration and to reproduce it with accuracy (Droit, 1995; Droit-Volet, 1998; Droit-Volet \& Gautier, 2000; Droit-Volet \& Rattat, 1999; Rattat \& DroitVolet, 2002). In these specific conditions, the target duration was automatically encoded through practice, without requiring that the children attend to time. This is consistent with the findings of other studies showing that people were able to incidentally learn and remember the duration of an event in retrospective timing situations, i.e., when they were tested on their perception of the duration of an event that they had previously experienced 
without knowing that its temporal properties were relevant (e.g., Boltz, 1992, 1995, 1998a, 1998b; Boltz, Kupperman, \& Dunne, 1998). For example, Boltz et al. (1998) showed that, as the degree of familiarity increased, retrospective estimation of the duration of a melody became more accurate, even though attentional resources were not specifically allocated to temporal information during the encoding phase. According to the authors, even if participants were presumably attending to nontemporal information, the event's duration should nonetheless be incidentally learned, thus explaining that experience improves the accuracy of temporal judgement. In young children, it is well known that the main source of difficulty in timing is related to their difficulties in allocating attention to time and keeping their attention focused until the end of the duration to be timed (e.g., Delgado \& Droit-Volet, in press; Droit-Volet, 2003a; Droit-Volet \& Clément, 2005). This difficulty would thus account for the results of Friedman (1990), which showed that children as young as 3 years were able to correctly recall the relative duration on a judgement scale going from "a very short time" to "a very long time" of some daily activities (e.g., drinking a glass of milk, watching a TV cartoon), for which the temporal experience has been sufficiently reactivated in memory to strength their memory traces.

However, at the age of 3 years, the specificity of duration learned procedurally is that the acquired duration remained associated with its original action. It is only from nearly 5 years of age that time and action are conceptually dissociated, that is to say that the children possessed an explicit concept of time (i.e., homogeneous time abstracted from events). As stated by Karmiloff-Smith $(1986,1992,1994)$, there is not a simple dichotomy in the age-related construction of knowledge between a pure procedural and a pure explicit knowledge. On the contrary, there is a hierarchy of knowledge levels going progressively from procedural implicit to explicit. The initial implicit knowledge is indeed progressively redescribed in an explicit format. In the knowledge of duration domain, the transition from a procedural implicit duration knowledge to a later explicit knowledge of time would occur between 3 and 5 years of age (Droit-Volet \& Rattat, 1999; Rattat \& Droit-Volet, 2002). In the present study, the developmental difference observed in the rate of forgetting of the learned duration between the age of 3 and 5 years could thus be explained by a relevant change in the time knowledge base during this age range. It is indeed conceivable that the older children spontaneously constructed a partial explicit knowledge of the duration of the action learned by imitation that facilitated its memorisation and/or retrieval in long-term memory.

In conclusion, our results showed that the children as young as 3 years were able to maintain in long-term memory the duration of an action that they acquired by imitation, i.e., procedural learning. Our findings are thus among the first to provide strong suggestions that, in young children, the 
nature of the memory system mediates the retention of durations, implicit long-term memory for duration being better than explicit long-term memory for duration.

Original manuscript received February 2006

Revised manuscript received May 2006

First published online 10 July 2006

\section{REFERENCES}

Anderson, J. R. (1983). Knowledge representation. In J. R. Anderson (Ed.), The architecture of cognition (pp. 45-85). Cambridge, MA: Harvard University Press.

Anooshian, L. J. (1997). Distinctions between implicit and explicit remembering: Significance for understanding cognitive development. International Journal of Behavioral Development, 21, 453-478.

Anooshian, L. J. (1998). Implicit and explicit memory in childhood: A review of relevant theory and research. Child Study Journal, 28, 17-52.

Anooshian, L. J. (1999). Understanding age difference in memory: Disentangling conscious and unconscious processes. International Journal of Behavioral Development, 23, 1-18.

Bauer, P. J. (1997). Development of memory in early childhood. In N. Cowan (Ed.), Development of memory in childhood (pp. 83-111). Hove, UK: Psychology Press.

Bauer, P. J., \& Hertsgaard, L. A. (1993). Increasing steps in recall of events: Factors facilitating immediate and long-term memory in 13,5- and 16,5-month-old children. Child Development, 64, 1204-1223.

Bauer, P. J., Hertsgaard, L. A., \& Dow, G. A. (1994). After 8 months have passed: Long-term recall of events by 1- to 2-year-old children. Memory, 2, 353-382.

Bauer, P. J., \& Mandler, J. M. (1989). One thing follows another: Effects on temporal structure on 1- to 2-year-olds' recall of events. Developmental Psychology, 25, 197-206.

Bauer, P. J., \& Shore, C. M. (1987). Making a memorable event: Effects of familiarity and organization on young children's recall of action sequences. Cognitive Development, 2, 327-338.

Block, R. A., Zakay, D., \& Hancock, P. A. (1999). Developmental changes in human duration judgments: A meta-analytic review. Developmental Review, 19, 183-211.

Boltz, M. G. (1992). The remembering of auditory event durations. Journal of Experimental Psychology: Learning, Memory, and Cognition, 18, 938-956.

Boltz, M. G. (1995). The relationship between internal and external determinants of time estimation behavior. In M. Richelle, V. de Keyser, G. D’Ydewalle, \& A. Vandierendonck (Eds.), Time and the dynamic control of behavior (pp. 93-121). Liège, Belgium: Pôle d'Attraction Interuniversitaire.

Boltz, M. G. (1998a). The processing of temporal and non temporal information in the remembering of event duration and musical structure. Journal of Experimental Psychology: Human Perception and Performance, 24, 1087-1104.

Boltz, M. G. (1998b). Task predictability and remembered duration. Perception and Psychophysics, $60,768-784$.

Boltz, M. G., Kupperman, C., \& Dunne, J. (1998). The role of learning in remembered duration. Memory and Cognition, 26, 903-921.

Cohen, J., MacWhinney, B., Flatt, M., \& Provost, J. (1993). PsyScope: An interactive graphic system for designing and controlling experiments in the psychology laboratory using Macintosh computers. Behavior Research Methods, Instruments and Computers, 25, 257-271. 
Delgado, M. L., \& Droit-Volet, S. (in press). Testing the representation of time in reference memory in the bisection and the generalization task: The utility of a developmental approach. Quarterly Journal of Experimental Psychology.

DiGiulio, D. V., Seidenberg, M., O’Leary, D. S., \& Raz, N. (1994). Procedural and declarative memory: A developmental study. Brain and Cognition, 25, 79-91.

Droit, S. (1995). Learning by doing in 3- and $4 \frac{1}{2} 2$-year-old children: Adapting to time. European Bulletin of Cognitive Psychology, 14, 283-299.

Droit-Volet, S. (1998). Time estimation in young children: An initial rule force governing production. Journal of Experimental Child Psychology, 68, 236-249.

Droit-Volet, S. (2000). L'estimation du temps: perspective développementale. L'Année Psychologique, $100,443-464$.

Droit-Volet, S. (2003a). Alerting attention and time perception in children. Journal of Experimental Child Psychology, 85, 372-384.

Droit-Volet, S. (2003b). Temporal experience and timing in children. In W. H. Meck (Ed.), Functional and neural mechanisms of interval timing (pp. 183-208). New York: CRC Press.

Droit-Volet, S., \& Clément, A. (2005). Time perception in children and adults: Effects of continuous and discontinuous signal. Current Psychology of Cognition, 23, 229-248.

Droit-Volet, S., Delgado, M., \& Rattat, A.-C. (2005). The development of the ability to judge time in children. In J. R. Marrow (Ed.), Focus on child psychology research (pp. 81-104). New York: Nova Science Publishers.

Droit-Volet, S., \& Gautier, T. (2000). Time estimation in young children: The role of instructions as a function of the type of response. Current Psychology of Cognition, 19, 263-276.

Droit-Volet, S., \& Rattat, A.-C. (1999). Are time and action dissociated in young children's time estimation? Cognitive Development, 14, 573-595.

Friedman, W. J. (1990). Children's representation of the pattern of daily activities. Child Development, 61, 1399-1412.

Friedman, W. J. (1991). The development of children's memory for the time of past events. Child Development, 62, 139-155.

Friedman, W. J., Gardner, A. G., \& Zubin, N. R. E. (1995). Children's comparisons of the recency of two events from the past year. Child Development, 66, 970-983.

Friedman, W. J., \& Kemp, S. (1998). The effects of elapsed time and retrieval on young children's judgments of the temporal distances of past events. Cognitive Development, 13, 335-367.

Greenbaum, J. L., \& Graf, P. (1989). Preschool period development of implicit and explicit remembering. Bulletin of the Psychonomic Society, 27, 417-420.

Howe, M. L., \& Brainerd, C. J. (1989). Development of children's long-term retention. Developmental Review, 9, 301-340.

Kail, R. (1990). The development of memory. New York: Freeman.

Karmiloff-Smith, A. (1986). From meta-processes to conscious access: Evidence from children's metalinguistic and repair data. Cognition, 23, 95-147.

Karmiloff-Smith, A. (1992). Beyond modularity: A developmental perspective on cognitive science. Cambridge: MIT Press.

Karmiloff-Smith, A. (1994). Precis of beyond modularity: A developmental perspective on cognitive science. Behavioral and Brain Sciences, 17, 693-745.

Lewis, P. A., \& Miall, R. C. (2003). Overview: An image of human neural timing. In W. H. Meck (Ed.), Functional and neural mechanisms of interval timing (pp. 515-532). New York: CRC Press.

Michon, J. A. (1990). Implicit and explicit representations of time. In R. A. Block (Ed.), Cognitive models of psychological time (pp. 37-58). Hillsdale, NJ: Lawrence Erlbaum Associates, Inc.

Murphy, K., McKone, E., \& Slee, J. (2003). Dissociations between implicit and explicit memory in children: The role of strategic processing and the knowledge base. Journal of Experimental Child Psychology, 84, 124-165. 
Naito, M. (1990). Repetition priming in children and adults: Age-related dissociation between implicit and explicit memory. Journal of Experimental Child Psychology, 50, 462-484.

O'Connel, B. G., \& Gerard, A. B. (1985). Script and scraps: The development of sequential understanding. Child Development, 56, 671-681.

Parkin, A. J., \& Streete, S. (1988). Implicit and explicit memory in young children and adults. British Journal of Psychology, 79, 361-369.

Rattat, A.-C., \& Droit-Volet, S. (2002). Le transfert d'apprentissage de durée d'action chez le jeune enfant: l'effet facilitateur de la variété des actions? Enfance, 54, 141-153.

Rattat, A.-C., \& Droit-Volet, S. (2005). The long-term retention of time: A developmental study. Quarterly Journal of Experimental Psychology, 58B, 163-176.

Russo, R. P., Nichelli, M., Gibertoni, M., \& Cornia, C. (1995). Developmental trends in implicit and explicit memory: A picture completion study. Journal of Experimental Child Psychology, 59, $566-578$.

Schneider, W. (2000). Research on memory development: Historical trends and current themes. International Journal of Behavioral Development, 24, 407-420.

Tartas, V. (2001). The development of systems of conventional time: A study of the appropriation of temporal locations by four-to-ten year old children. European Journal of Psychology of Education, 16, 197-208.

Tulving, E. (1985). How many memory systems are there? American Psychology, 40, 385-398. 